\title{
Redaksioneel
}

\section{Navorsing in die Fakulteit Teologie (Afd A), Universiteit van Pretoria}

Die taak van die kerklike hoogleraar en dosent word deur die Kerkwet omskrywe. Sy opdrag is drieledig van aard. Die belangrikste deel hiervan is die opleiding van predikante vir die Nederduitsch Hervormde Kerk van Afrika. Onontbeerlik as onderbou van sy primêre taak, word daar van die dosent in die teologie verwag om op 'n wetenskaplike wyse die teologiese arbeid te bevorder. Teologie word egter nie ter wille van die wetenskap op sigself beoefen nie. Dit is daarom in die derde plek die taak van die dosent om ook die Kerk van advies te bedien ter wille van die voortgang van die verkondiging van die evangelie. Die Hervormde Teologiese Studies is 'n medium waarin baie van die navorsingsresultate van die Kerk se teoloë gepubliseer word. Bydraes op die gebied van die teologie en aanverwante wetenskappe wat uit kringe buite die Nederduitsch Hervormde Kerk kom, word graag ontvang met die oog op publikasie.

In die redaksionele voorwoord van dié betrokke Aflewering word 'n oorsig gepubliseer van die navorsing waarmee die lede van die Fakulteit Teologie (Afd A) aan die Universiteit van Pretoria tans besig is. Aspekte van die resultate daarvan is reeds in die vorm van boeke of artikels gepubliseer en ook in memoranda as advies aan sekere kerklike liggame beskikbaar gestel.

In die Departement Dogmatiek en Christelike Etiek het prof BJ Engelbrecht, hoof van die Departement en dekaan van die Fakulteit, hom veral besig gehou met die verhouding teologie-ekologie. Prof GC Velthuysen doen navorsing oor die Godsbegrip met die oog op die rol van die kerk en teologie in die moderne tydsgewrig. Prof JH Koekemoer se aandag word, naas sy ondersoek na die teologie van Dietrich Bonhoeffer, veral opgeëis om as direkteur van die nuutgestigte Sentrum vir Voortgesette Teologiese Toerusting kursusse in hierdie verband te implementeer.

Die hoof van die Departement Ou-Testamentiese Wetenskap, prof JP Oberholzer, is die aangewese dekaan van die Fakulteit. Hy is besig met navorsing oor onder andere die Skrifgebruik in die Belydenisskrifte, met die opstel van 'n Hebreeus-Afrikaanse woordeboek en 'n konkor- 
dansie van die Nuwe Afrikaanse Bybelvertaling. Proff APB Breytenbach en PM Venter is betrokke by ' $n$ opgrawingsprojek van prof $W C$ van Wyk, dekaan van die Fakulteit Lettere en Wysbegeerte, in Lagis, Israel. Prof van Wyk is deeltydse dosent in die Departement Ou-Testamentiese Wetenskap met opdrag Argeologie. Prof Breytenbach se navorsing is toegespits op die vraag na die gesag van die Ou Testament en dié van prof Venter op die kanon van die Ou Testament.

Prof AD Pont, hoof van die Departement Kerkgeskiedenis, se oorhoofse navorsingsprojek is die wordingsgeskiedenis van die Nederduitsch Hervormde Kerk met as onderdele die kerklike orde, die invloed van die liberalisme en 'n biografie van ds Dirk van der Hoff. In die Departement Praktiese Teologie doen prof TFJ Dreyer navorsing oor bedieningstrukture met die oog op die jaar 2000. Prof PJ van der Merwe, hoof van die Departement Godsdiens- en Sendingwetenskap, lewer 'n groot inset met betrekking tot die herkurrikulering van leerplanne in die Fakulteit en is ook besig met die opstel van 'n thesaurus op mikro-rekenaar van publikasies op die gebied van die Godsdienswetenskap. Prof JJ Engelbrecht, verbonde aan die Departement Bybelkunde, se navorsing handel oor die vraag na die verhouding van Bybelkunde tot die Bybelwetenskappe, veral wat leerinhoude vir graadvereistes betref.

Die Departement Nuwe-Testamentiese Wetenskap is as departement in geheel besig met navorsing oor die bydrae van die sosiologiese agtergrond van die Nuwe Testament vir die eksegese. Prof JJ Engelbrecht van die Departement Bybelkunde is ook by hierdie projek ingeskakel. Prof GMM Pelser, hoof van die Departement NuweTestamentiese Wetenskap, is besig met 'n redevoeringsanalitiese kommentaar op 2 Korintiërs, afgestem op die praktyk van die prediking. Hy doen ook navorsing oor die Pauliniese antropologie en oor Rudolf Bultmann se siening oor die opstanding van Jesus uit die dood en die eskatologie. Prof AG van Aarde doen 'n ondersoek na die aanknopingspunte by die aardse Jesus waarmee probleme in die vroegste Siriese kerk aangespreek is. Daarnaas is sy navorsing toegespits op die bydrae van moderne literatuurteorieë vir die eksegese van die Matteus- en die Johannesevangelie en op 'n ondersoek na temas in 1 Tessalonisense wat opgeneem en herinterpreteer is deur die skrywer van 2 Tessalonisense as 'n pseudo-Paulusbrief. Proff van Aarde en Pelser is ook op uitnodiging betrokke by seminaargroepwerk van die internasionale vakvereniging, die Studiorum Novi Testamenti Societas, oor die bydrae wat ' $n$ literatuurteoretiese analise van die implisiete lesersrol en van die 
leeshandelingsproses kan lewer vir die bepaling van die betekenis van Nuwe-Testamentiese tekste. Vir dié doel het hulle gedurende Augustus 1986 die Emory Universiteit in Atlanta, VSA en gedurende Augustus 1987 die Georg-August Universiteit in Göttingen, Wes-Duitsland besoek. 